\title{
Effects of Laughter Therapy on Anxiety, Stress, Depression and Quality of Life in Cancer Patients
}

\section{Melike Demir*}

Gümüşhane University, School of Health, Gümüşhane, Turkey

\begin{abstract}
Introduction: The quality of life of cancer patients is affected by the cancer therapy's symptoms. Anxiety, stress, and depression all affect cancer patients thus reducing the life style of the patient. The aim of this review was to determine the effects of laughter therapy on anxiety, stress, depression, and quality of life in cancer patients.

Methods: Articles were searched on PubMed and Google Scholar. This review includes randomized controlled trials and case reports from 2000-2015.

Results: 41 studies were found on PubMed and 14,700 studies were found on Google Scholar search. Only two articles met the established review criteria in PubMed and four articles met the established review criteria in Google Scholar. In total, six articles were included in the study.
\end{abstract}

Conclusion: The results of this study show that laughter therapy may decrease anxiety, stress, and depression and increase the quality of life in cancer patients.

Keywords: Laughter therapy; Anxiety; Stress; Depression; Quality of life; Cancer patients

\section{Introduction}

Cancer has increasingly been recognized as a chronic illness. Cancer affects patients on physiological, social, and psychological levels [1]. Treatment of cancer persists for long periods after diagnosis and causes many side effects such as pain, stress, depression, anxiety and decreased quality of life. Stress is $24.8 \%$, depression is $24.0 \%$ and anxiety is $24.0 \%$ in patients receiving cancer treatment $[2,3]$.

Laughter has positive, quantifiable physiological and psychological effects on certain aspects of health [4]. Laughing therapy, a cognitivebehavioral therapy, is located within the complementary alternative therapies and has been regarded as a long-standing complementary and alternative therapy since $1970[5,6]$

Laughter therapy is an application containing breathing exercises and physical movement. Laughter exercises start with proper breathing exercises and then laughter is achieved by using play, clowning, dancing and movement $[4,6]$.

Laughter is universally well tolerated and it has very limited side effects. Laughing therapy relaxes the muscles and improves breathing. It raises the pain threshold, increases tolerance and improves psychological well-being. It also increases friendliness and collaboration and facilitates group identity, solidarity and cohesiveness [6]. By decreasing stress-making hormones floating in the blood, laughter removes the effects of stress [11]. Some studies have shown that laughter therapy is effective on anxiety $[5,7,8]$, depression $[5,7,9,10]$, stress $[5,7,11]$, quality of life [9], insomnia [8,10], sleep quality [10], and radiation dermatitis [12].

So the aim of this review was to determine the effects of laughter therapy on anxiety, stress, depression, and quality of life in cancer patients.

\section{Methods}

Articles were researched in PubMed and Google Scholar. This review includes randomized controlled trials and case reports from
2000-2015. The following search limits were utilized: (a) English only; (b) random assignment, either placebo or control; case reports (c) peer-reviewed journals; (d) abstracts; (e) full text. We searched for cancer, laughter therapy, randomized controlled study and case reports as keywords. We found 41 studies in the PubMed search and 14,700 studies in the Google Scholar search. Only two articles met the established review criteria in PubMed and four articles met the established review criteria in Google Scholar

\section{Results and Discussion}

Six articles met the established review criteria, four of them in Google Scholar and two in PubMed. One of the studies, which was done to determine the effect of laughter therapy on the cancer patients' stress levels before chemotherapy, reported that laughter therapy decreased the patients' stress levels before chemotherapy $(\mathrm{p}=0.03)$ (Table 1). In this study, the experimental group $(n=23)$ was treated with laughter therapy for 20 to 30 minutes under a researcher's observation. The control group involved 14 patients and the two groups' stress levels were evaluated before and after laughter therapy with the Questionnaire on Stress in Cancer Patients [11].

Another randomized controlled study involved 31 breast cancer patients who received four sessions of the therapeutic laughter program and 29 breast cancer patients who were assigned to the no-program control group (Table 1). After the first therapeutic laughter session, patients' anxiety, depression and stress levels decreased significantly in the experimental group. There was no change in the control group. In

*Corresponding author: Melike Demir, Gumushane University School of Health Sciences, Bağlarbaşı Mahallesi 29100 / Gümüşhane, Turkey, Tel: 05334828957; E-mail: melekdm@gmail.com

Received June 08, 2015; Accepted August 20, 2015; Published August 22, 2015

Citation: Demir M (2015) Effects of Laughter Therapy on Anxiety, Stress, Depression and Quality of Life in Cancer Patients. J Cancer Sci Ther 7: 272-273. doi:10.4172/1948-5956.1000362

Copyright: (c) 2015 Demir M. This is an open-access article distributed under the terms of the Creative Commons Attribution License, which permits unrestricted use, distribution, and reproduction in any medium, provided the original author and source are credited. 
Citation: Demir M (2015) Effects of Laughter Therapy on Anxiety, Stress, Depression and Quality of Life in Cancer Patients. J Cancer Sci Ther 7: 272-273. doi:10.4172/1948-5956.1000362

\begin{tabular}{|l|l|l|l|}
\hline Studies & Sample & Methots & Results \\
\hline Farifteh et al. [11] & $\begin{array}{l}\text { experimental }(n=23) \\
\text { Control }(n=14)\end{array}$ & laughter therapy for 20 to 30 minutes & decreased the patient' stress levels before chemotherapy $(p=0.03)$ \\
\hline Kim et al. [5] & $\begin{array}{l}\text { Experimental }(n=31) \\
\text { Control }(n=29)\end{array}$ & $\begin{array}{l}\text { four sessions of therapeutic laughter } \\
\text { program }\end{array}$ & $\left.\begin{array}{l}\text { single session for reducing anxiety }(p<0.01) \text {, depression }(p<0.01) \text { and stress }(p< \\
0.01\end{array}\right)$ \\
\hline Kim et al. [7] & $\begin{array}{l}\text { Experimental }(n=31) \\
\text { Control }(n=29)\end{array}$ & $\begin{array}{l}\text { laughter therapy } 4 \text { times for } 2 \text { weeks } \\
\text { and each session lasted } 60 \text { min. }\end{array}$ & Depression $(p<0.01)$, anxiety $(p=0.04)$, stress $(p<0.01)$ were decrease \\
\hline Han et al. [15] & $\begin{array}{l}\text { Experimental }(n=23) \\
\text { Control }(n=17)\end{array}$ & $\begin{array}{l}\text { one hour laughter therapy consisting } \\
\text { of dance, lots of laughter techniques, } \\
\text { and meditation }\end{array}$ & $\begin{array}{l}\text { mood and anxiety were significantly improved. } \\
\text { No difference was found in serum cortisol. }\end{array}$ \\
\hline
\end{tabular}

Table 1: Randomized controlled studies about laughter therapy

conclusion, this study reported that laughter therapy was effective after only a single session in reducing anxiety, depression and stress in breast cancer patients $(\mathrm{p}<0.01, \mathrm{p}<0.01$, and $\mathrm{p}<0.01)$ [5].

A quasi-experimental study using pretest-posttest design included 37 breast cancer patients who had finished chemotherapy and radiation therapy. In this study, the experimental group $(n=16)$ had laughter therapy twice a week for $60 \mathrm{~min}$ per session for a total of eight times. The results of this study reported that laughter therapy was an effective approach for quality of life, but wasn't an effective approach towards depression and immune responses in breast cancer survivors [13].

A case of a patient diagnosed as having advanced gastric cancer showed that laughter therapy had the effect of reducing the stress experienced and the patient maintains a good condition five years after the initial diagnosis [14].

Another study, which was to investigate the effect of laughter therapy on depression, anxiety, and stress among patients receiving radiotherapy, included 60 breast cancer outpatients (Table 1). The experimental group $(n=31)$ had laughter therapy four times for two weeks and each session lasted $60 \mathrm{~min}$. Consequently, this study reported that degrees of depression, anxiety, and stress were decreased significantly $(\mathrm{p}<0.01, \mathrm{p}=0.04$, and $\mathrm{p}<0.01)$ [7].

A randomized controlled study done on 40 preoperative breast cancer patients reported that the scores of anxiety were significantly improved in the experimental group (Table 1). 23 breast cancer patients were included in the experimental group and 17 breast cancer patients in the control group. The experimental group underwent laughter therapy for one hour consisting of dance, lots of laughter techniques, and meditation [15].

A meta-analysis done to determine effective intervention on depression in cancer patients showed that laughter therapy wasn't effective on depression in cancer patients [16].

\section{Conclusion}

Laughter therapy may decrease anxiety, stress, and depression and increase quality of life in cancer patients. There is a need to conduct further work to find conclusive evidence.

\section{References}

1. Tsang KL, Carlson LE, Olson K (2007) Pilot crossover trial of Reiki versus rest for treating cancer-related fatigue. Integr Cancer Ther 6: 25-35.

2. Carlson LE, Angen M, Cullum J, Goodey E, Koopmans J, et al. (2004) High levels of untreated distress and fatigue in cancer patients. $\mathrm{Br} \mathrm{J}$ Cancer 90: 2297-2304.

3. Sikorskii A, Wyatt G, Siddiqi A, Tamkus D (2011) Recruitment and early retention of women with advanced breast cancer in a complementary and alternative medicine trial. Evid Based Complement Alternat Med 7.
4. Mora Ripoll R (2013) Laughter techniques for therapeutic use in medicine. OA Alternative Medicine 1: 25

5. Kim SH, Kim YH, Kim H J (2015) Laughter and Stress Relief in Cancer Patients: A Pilot Study. Evidence-Based Complementary and Alternative Medicine: 1-6.

6. Ripoll RM, Casado IQ (2010) Laughter and Positive Therapies: Modern Approach and Practical Use in Medicine. Rev Psiquiatr Salud Ment (Barc.) 3: 27-34.

7. Kim SH, Kim YH, Kim HJ, Lee SH, Yu SO (2009) The Effect of Laughter Therapy on Depression, Anxiety, and Stress in Patients with Breast Cancer Undergoing Radiotherapy. J Korean Oncol Nurs 9: 155-162.

8. Ghodsbin F, Ahmadi ZS, Jahanbin I, Sharif F (2015) The effects of laughter therapy on general health of elderly people referring to jahandidegan community center in Shiraz, Iran, 2014: a randomized controlled trial. International Journal of Community Based Nursing and Midwifery 3: 31

9. Shahidi M, Mojtahed A, Modabbernia A, Mojtahed M, Shafiabady A et al. (2011) Laughter yoga versus group exercise program in elderly depressed women: a randomized controlled trial. International Journal of Geriatric Psychiatry 26: 322-327.

10. Ko H, Youn C (2011) Effects of laughter therapy on depression, cognition and sleep among the community-dwelling elderly. Geriatrics \& Gerontology International 11: 267-274

11. Farifteh SH, Mohammadi-Aria AR, Kiamanesh AR, Mofid B (2014) The Impact of Laughter Yoga on the Stress of Cancer Patients before Chemotherapy. Iran J Cancer Prev 7: 179-83.

12. Kong M, Shin S, Lee E, Yun E (2014) The effect of laughter therapy on radiation dermatitis in patients with breast cancer: a single-blind prospective pilot study. OncoTargets and Therapy 7: 2053-2059.

13. Cho EA, Oh HE (2011) Effects of laughter therapy on depression, quality of life resilience and immune responses in breast cancer survivors. Journal of Korean Academy of Nursing 41: 285- ${ }^{\text {TM }} 293$

14. Noji S, Takayanagi K (2010) A case of laughter therapy that helped improve advanced gastric cancer. Jpn Hosp 29: 59-64.

15. Han H, Park A, Kim HS, Moon H, Park Y (2011) The Effects of Laughter Therapy on Stress Responses in Patients with Preoperative Breast Cancer. J Korean Oncol Nurs 11: 93-100.

16. Jang EH, Choi KS, Kwon SJ (2013) A Meta-analysis of Intervention on Depression in Cancer Patients. Asian Oncol Nurs 13: 1-10. 